\title{
Una aproximación a la descolonización de los estudios de paz: la experiencia intercultural y de abajo del pueblo Nasa Wes'x Tolima, Colombia ${ }^{1}$
}

\author{
An Approach to the decolonization of peace studies: The intercultural \\ experience and top to bottom of the people Nasa Wes'x Tolima-Colombia
}

\section{Uma aproximação da descolonização dos estudos de paz: a experiência intercultural desde o povo Nasa Wes'x Tolima - Colômbia}

\author{
Eduardo Andrés Sandoval-Forero ${ }^{2}$ \\ Universidad Autónoma del Estado de México, México \\ https://orcid.org/0000-0003-1659-7588 \\ José Javier Capera Figueroa ${ }^{3}$ \\ Universidad Iberoamericana Ciudad de México - Tijuana \\ https://orcid.org/0000-0003-1823-2814
}

Recepción: 15/03/2020

Evaluación: 17/04/2020

Aceptación: 28/05/2020

Artículo de Investigación - Revisión

https://doi.org/10.19053/01227238.11939

\section{RESUMEN}

El objetivo del artículo consiste en discutir teórica y conceptualmente el paradigma tradicional de la investigación moderno/colonial desde una perspectiva de paz descolonizadora a partir de la experiencia intercultural del pueblo Nasa Wes'x Tolima (Colombia), con respecto al conflicto entre los actores legales e ilegales inmersos en sus territorios. La origina- lidad consiste en abordar la problemática desde la ruptura epistémica de la interculturalidad para la paz. El método utilizado fue el de la investigación fundamentada a partir de análisis de texto y de discursos de los indígenas, concluyendo que la experiencia de paz del pueblo Nasa Wes'x se articula con la perspectiva descolonizadora e intercultural de la paz,

1 Este artículo de investigación hace parte del proyecto inter-comunitario/universitario denominado "Epistemologías decoloniales para la paz en el Sur-Global-Homenaje al filósofo del pensamiento antihegemónico Álvaro Ballardo Márquez-Fernández”, a cargo de la Red Constructores de Paz Latinoamericana, el fondo de publicaciones del Laboratorio de Investigaciones Semióticas y Literarias (LISYL) - Universidad de los Andes (Venezuela), la Red de Pensamiento Decolonial (capítulos latinoamericano y francés) y Arkho Ediciones. Se agradece la corrección y revisión de estilo de la literata Indira Enríquez.

2 Doctor en Sociología de la Universidad Nacional Autónoma de México. Maestro en Estudios Latinoamericanos, Universidad Autónoma del Estado de México y antropólogo social de la Escuela Nacional de Antropología e Historia (México). Miembro del Sistema Nacional de Investigadores de México, nivel III. Profesor invitado de universidades de Estados Unidos, América del Sur, España e Italia. Fundador y coordinador académico de la Maestría y el Doctorado en Educación para la Paz y la Convivencia Escolar en México. Investigador-Profesor del CIEAP, Universidad Autónoma del Estado de México. Correo electrónico: forerosandoval@gmail. com

3 Doctorando en Ciencias Sociales y Políticas de la Universidad Iberoamericana (México). Maestro en Sociología Política del Instituto de Investigaciones Dr. José María Luis Mora. Politólogo de la Universidad del Tolima. Analista político y columnista del periódico El Nuevo Día (Colombia) y Rebelión.org (España).Correo: caperafigueroa@gmail.com [http://josecaperafigueroa.blogspot.mx/] 
al enjuiciar los esquemas tradicionales de pacificación promovidos desde los intereses y dinámicas del Estado hegemónico; por el contrario, apela a la autonomía y liberación de la madre tierra, siendo el reflejo del sentipensar desde los territorios en el marco de la construcción de paces como la motivación de sus propias luchas por otra realidad posible en el ámbito comunitario.

Palabras clave: Descolonialidad; estudios para la paz; Nasa Wes'x; Colombia; sociología emergente.
The objective of the article is to discuss in a theoretical and conceptual way the traditional paradigm of modern / colonial research from a decolonizing peace perspective based on the intercultural experience of the people. Nasa Wes'x Tolima - Colombia, regarding the conflict between legal and illegal participants immersed in their territories. The originality consists in addressing the problem from the epistemic rupture of interculturality for peace. The method applied was the text analysis research based on indigenous discourses, concluding that the experience of peace of people Nasa Wes' $x$ joint with the decolonizing and intercultural perspective of peace, when judging the traditional schemes of pacification promoted from the hegemonic State's interests and dynamics, on the contrary, it appeals to the autonomy and liberation of the mother earth being the reflection of the thought-feeling from the territories in the framework of the peace construction as the motivation of their own struggles for another possible reality in the community sphere.

Key words: Decoloniality; Studies for the Peace; Nasa Wes'x; Colombia; Emerging Sociology.

\section{RESUMO}

O objetivo do artigo consiste em discutir teórica e conceitualmente o paradigma tradicional da pesquisa moderno/ colonial de uma perspectiva da paz descolonizadora, a partir da experiência intercultural do povo.

Nasa Wes'x Tolima - Colômbia, com respeito ao conflito entre os atores legais e ilegais imersos em seus territórios. A originalidade consiste em abordar a problemática desde a ruptura acadêmica da interculturalidade para a paz. $\mathrm{O}$ método utilizado foi a pesquisa fundamentada a partir da análise de texto e de discursos dos indígenas, concluindo que a experiência de paz do povo Nasa Wes'x se articula com a perspectiva descolonizadora e intercultural da paz, ao processar os esquemas tradicionais de pacificação promovidos a partir dos interesses e dinâmicas do Estado hegemônico, pelo contrário, apela para a autonomia e libertação da mãe terra sendo reflexo do sentipensar a partir dos territórios no marco da construção da paz como a motivação de suas próprias lutas por outra realidade possível no contexto comunitário.

Palavras-chave: Descolonialidade; Estudos para a Paz; Nasa Wes'x; Colômbia; Sociologia Emergente.

\section{INTRODUCCIÓN}

El debate moderno sobre la construcción de un estatus científico de las ciencias en el siglo XX representó un escenario de largo alcance entre la comunidad académica y las universidades en una dinámica globalizadora. La tarea de 
promover paradigmas, métodos, enfoques y metodologías desde las corrientes dominantes como son: el positivismo, el historicismo, el racionalismo y la teoría crítica/clásica, se instituyó en un esquema predominante que genera una identidad sobre el quehacer en las disciplinas del conocimiento que incorporan las ciencias sociales y las humanidades.

Los estudios de paz no fueron ajenos al contexto social, político, económico y científico, que se caracterizó por impulsar la necesidad de la investigación en el campo de los conflictos, la violencia, la guerra y los intereses bélicos entre los gobiernos de la Europa de las guerras mundiales. Por ello, la emergencia de analizar la paz más allá de los intereses armamentista en la mitad del siglo XX representó el escenario por excelencia de dicho campo del conocimiento de las ciencias sociales ${ }^{4}$. Parte de esta apuesta respondía a una idea de la restructuración de los contenidos epistémicos que requerían las disciplinas nomotéticas de los estudios sociales, para que lograran interactuar de forma más pertinente, crítica e intersubjetiva con la realidad social y los problemas que acomplejaban la sociedad moderna.

La situación de complejizar las narrativas epistémicas sobre la configuración de conceptos, temas, fenómenos y problemáticas que fueran de gran relevancia para el análisis multidimensional provenientes de los estudios de paz implicarían la capacidad de comprender los contextos mediados por el conflicto, las paces y violencias, debido a las dinámicas de choques y correlación de fuerzas en un determinado escenario, tiempo y espacialidad. A su vez sería la base para reflexionar sobre los estatus epistémicos de este campo de investigación en función de la construcción de una disciplina en constantes devenires teórico-metodológicos, acorde con su condición eurocentrada del conocimiento.

En efecto, las narrativas provenientes de las discusiones sobre el desarrollo de los paradigmas estuvieron fundamentada en la diatriba por establecer los cánones que generaría la concepción de validez, la falsedad, la cientificidad o la demostración empírico-analítica, que requería la investigación con respecto a los fenómenos sociales que constituyen las problemáticas de las sociedades modernas en el desarrollo del sistema mundo-capitalista y la globalización liberal de la ciencia ${ }^{5}$.

Tal como lo describe Immanuel Wallerstein, al reconocer que:

En el curso del siglo XIX las diversas disciplinas se abrieron como un abanico para cubrir toda una gama de posiciones epistemológicas. En un extremo se hallaba primero la matemática (actividad no empírica), y a su lado las ciencias naturales experimentales (a su vez en una especie de orden descendente de determinismo -física, química, biología). En el otro extremo estaban las humanidades (o artes y letras) $[\ldots] .^{6}$

4 Immanuel Wallerstein, coord., Abrir las ciencias sociales: Informe de la Comisión Gulbenkian para la reestructuración de las ciencias sociales (México: UNAM / Siglo XXI editores, 1996).

5 Immanuel Wallerstein, Análisis de sistemas-mundo. Una introducción (México: Siglo XXI editores, 2005).

6 Wallerstein, Abrir las ciencias sociales, 12. 
La discusión epistémica de plantear un campo de los estudios de paz entre el paradigma de la investigación cualitativa y cuantitativa representó un camino por pluralizar los debates internos/externos que conforman las investigaciones tradicionales, clásicas o sociales en el espectro de los conflictos, las violencias y las paces en los diversos ámbitos de la esfera pública. Por ende, el sentido de impulsar la paz como una herramienta para la unificación estatal y la superación de las grietas conflictivas resultó ser una muestra enfocada a descubrir la oportunidad de generar formas de control y sumisión materializadas en la dominación o emancipación de la ciudadanía con respecto a los procesos políticos instituidos de las estructuras monolíticas del Estado moderno.

Las observaciones y misiones internacionales, promovidas en el año de 1940 en el marco de conflictos bélicos como la Primera Guerra Mundial, y en aquel momento la Segunda Guerra Mundial, simbolizó el interés central y colonizador de convertir la paz como una política de Estado que lograra subsanar los déficits existentes de las democracias y los autoritarismos políticos de los gobiernos sumidos en prácticas políticas de exclusión, violencia y belicismo, es decir, los autoritarismos y totalitarismos tanto de izquierda y derecha ${ }^{7}$. A su vez, el corpus epistémico proveniente de la oportunidad de problematizar desde una perspectiva tradicional, clásica o crítica propia de la corriente eurocéntrica cimentada en el trinomio paz-conflicto-violencia, despertó para las escuelas de pensamiento europeas una coyuntura pertinente para las ciencias sociales y su desarrollo en los procesos políticos en materia de la resolución de conflictos o pacificación que instituye la condición humana y la necesidad de normalización de los procesos socio-políticos que conforman las instituciones del Estado capitalista ${ }^{8}$.

Por tal motivo, los estudios de paz pasaron a ser un campo de relevancia para la investigación empírica o social, aunque cargaron con el velo del colonialismo interno y epistémico europeo, y la hegemonía de un tipo de ciencia funcional a los requerimientos de los grupos de arriba afines a los intereses del capitalismo moderno-colonialista 9 . La apuesta por producir un tipo de conocimiento en términos de paz, vinculado a los intereses pragmáticos de los Estados nacionales representaría la encrucijada colonial de dicho campo del conocimiento que se enfrentaba a darle mayor preponderancia a la racionalidad instrumental del Estado o las formas de expresión de lo político, la crítica política y la resistencia de la sociedad civil en las diversas regiones víctimas de los conflictos armados ${ }^{10}$.

La necesidad de entender la difícil situación de orden ético-político que represente el conflicto, el cual tiene una serie de procedimientos de orden teórico-metodológico, de gran interés para el campo de reflexión de los estudios paz, implica asumir una grieta a dicha corriente disciplinar y tradicional

7 Fernando Harto de Vera, "La construcción del concepto de paz: paz negativa, paz positiva y paz imperfecta”, Cuadernos de estrategia, n. ${ }^{\circ} 183$ (2016).

8 Francisco Jiménez, "Hacia un paradigma pacífico: La paz neutra", Convergencia. Revista de Ciencias Sociales, n. ${ }^{\circ}$ extraordinario 1 (2009).

9 Julio César Alvear, “La paz neoliberal: el postulado de la razón instrumental sobre la razón dialógica”, Criterio Jurídico vol. 8 , n. 2 (2008).

10 Zulay Díaz, "Pensar del sujeto interdiscursivo en el diálogo intercultural", Utopía y Praxis Latinoamericana vol. 18, n. ${ }^{\circ} 60$ (2013). 
del conocimiento, para así suscitar la emergencia de paradigmas subalternos y descolonizadores, que apuestan por ir más allá de la narrativa oficial e institucional del poder político hegemónico, el cual enajena y promueve una cultura e imaginario de sumisión, control y manipulación en contravía de los intereses reales y nobles propios de la liberación y lucha desde abajo que emprenden las comunidades, la sociedad civil emancipada y los movimientos sociales sobre el rol de la democratización de la esfera pública en el marco de la horizontalidad de los poderes públicos moderno-institucionales.

Por el contario, frente a la visión eurocentrada de los estudios de paz, toman fuerza las narrativas subalternas de orden teórico-conceptual y con gran potencia metodológica, expuestas por Cruz y Fontan ${ }^{11}$, Sandoval ${ }^{12}$ y Cruz ${ }^{13}$, sobre el campo de los estudios de paz, al reconocer la preponderancia que existe de la perspectiva epistémica eurocéntrica sobre los temas, discusiones y enfoques que configuran la paz o paces como un espacio de investigación en las ciencias sociales colonizadas. A su vez, mencionan la vitalidad de promover análisis desde las experiencias/casos de los grupos vulnerados, de abajo o en resistencias como situaciones descolonizadoras que hagan frente a las olas de violencias sistémicas provenientes de los grupos hegemónicos y estatales en el marco de la sociedad neoliberalizada y el paradigma del desarrollo capitalista.

La oportunidad de impulsar investigaciones sobre los conflictos, los racismos, la xenofobia y los fenómenos socio-culturales que intervienen en situaciones de violencia son parte del repertorio de análisis de los estudios para la paz que observan desde la descolonización los escenarios conflictivos proclives a ser generadores de situaciones de violencias sistémicas ${ }^{14}$. Así pues, la emergencia de constituir contextos de pacificación, conciliación y democratización de las paces desde una perspectiva integral, simboliza parte de la narrativa por superar el colonialismo epistémico e interno de la paz neoliberal que es reproducida por los organismos internacionales sumidos en la dinámica del sistema mundo-capitalista $^{15}$.

Por ende, es importante reconocer que:

Cuando hablamos de paz nos estamos refiriendo también a las situaciones de conflicto. La paz se conforma por aquellos escenarios de no conflicto antagónico, de no exclusión, de no intolerancia, de no violencia, de no discriminación y de no abusos. Con esto queremos decir que unas herramientas importantes para construir la paz son la negociación, el diálogo, la mediación y la transformación pacífica de los conflictos a partir del diálogo, las leyes, los derechos humanos y el reconocimiento de todas las diversidades culturales, étnicas, religiosas, políticas y sociales

11 Juan Cruz y Victoria Fontan, "Una mirada subalterna y desde abajo de la cultura de paz", Ra Ximhai vol. 10, n. 2 (2014).

12 Eduardo Sandoval, Educación para la paz integral. Memoria, interculturalidad y decolonialidad (Bogotá: ARFO, 2016).

13 Juan Cruz, "Los estudios de paz latinoamericanos en la encrucijada. Producir o reproducir, una mirada desde las epistemologías del Sur", Revista CoPaLa vol. 3, n. ${ }^{\circ} 5$ (2018).

14 Cruz y Fontan, "Una mirada subalterna".

15 Immanuel Wallerstein, Historia y dilemas de los movimientos antisistémicos (Bogotá: Ediciones desde abajo, 2008). 
que permitan el fortalecimiento de las instituciones encargadas de garantizar $y$ promover el bienestar social. ${ }^{16}$

La exigencia histórica de comprender el surgimiento de los estudios de paz en la sociedad moderna tiene que ver con la construcción de propuestas de pacificación desde el campo de estudio de los analistas de la violencia, afines a corrientes como el liberalismo y el funcionalista en primera instancia, las cuales se caracterizaron por promover la razón instrumental del Estado capitalista y la dinámica de despojo, violencia y conflicto negativo de la sociedad neoliberalizada. Por ende aparecen los primeros centros, universidades, escuelas, programas e instituciones orientadas a la investigación para la paz desde el ámbito de la educación superior, lo cual implica la articulación de temáticas como la cultura, los conflictos, la política y la resolución de situaciones de violencia en el marco de la pacificación de los grupos tradicionales hacedores de un imaginario de cooptación/dominación y sumisión funcionales a la naturaleza del poder modernocolonizador.

Parte de este panorama refleja la fuerza que asumió la perspectiva hegemónica de los estudios bélicos en medio de las guerras imperfectas y devastadoras, que sirvieron como insumo para la configuración de una mirada institucionalizada, liberal, privada y sistémica de la paz vista desde el Norte-Global ${ }^{17}$. Al convertirse, en un imperativo moderno de los gobiernos en su afán de imponer un modelo político de democracia procedimental/liberal, a través del control y normalización de las violencias en el interior de sus estructuras institucionales del poder moderno ${ }^{18}$.

La agenda teórico-política auspiciada por los organismos internacionales y las instituciones público--privadas funcionales al poder hegemónico, lograron imponer en los establecimientos educativos formales e informales la apuesta de una paz de orden liberal, la cual se instaura como un instrumento de control encaminado a la mercantilización, la privatización y el corporativismo de las narrativas de paces derivadas de las luchas de los grupos en resistencia o víctimas de las violencias en sus territorios, lo que refleja un conjunto de normas, procedimientos, reglamentos y requisitos de naturaleza moderno/coloniales propios de una perspectiva de la democracia moderna/liberal-capitalista ${ }^{19}$.

Por tanto, parte de este conjunto de conocimientos de naturaleza positivista, lineales y sistémicos, demuestran tener una fuerte influencia de dicho paradigma en la construcción epistémica de los estudios para la paz, pues contempla que:

16 Sandoval, Educación para la paz integral, 24-25.

17 Julio Jaime-Salas, "Descolonizar los Estudios de Paz, un desafío vigente en las Ciencias Sociales en el marco de la neoliberalización epistémica contemporánea”, Revista de Paz y Conflictos vol. 12, n. ${ }^{\circ} 1$ (2019).

18 Boaventura de Sousa Santos, "Colombia entre la paz neoliberal y la paz democrática" (2017). Obtenido de Kavilando: https://kavilando.org/index.php/2013-10-13-19-52-10/confllicto-social-y-paz/5223-colombia-entre-la-paz-neoliberal-y-la-paz-democratica-1. (feb., 2020).

19 Juan Cruz, "Reseña del libro Descolonización de la paz de Victoria Fontan”, Ra Ximhai vol. 10, n. 2 (2014). 
La paz implica, al igual que la violencia, variados entornos de la vida del hombre, por ello referirnos solo a un tipo de paz o a un tipo de conflicto o de violencia, resulta poco cercano a la realidad, pues cada continente, país, región, estado, municipio o localidad, presenta contextos sociales y culturales históricos y del presente, que le impregnan su condición particular de aplicarse, abordarse, entenderse y de enseñarse. ${ }^{20}$

La necesidad de superar el velo del colonialismo epistémico desde la posibilidad de establecer un diálogo inter-subjetivo entre los actores y la praxis por superar la crisis civilizatoria involucra darle sentido a los estudios de paz desde abajo, puesto que consiguen cuestionar fenómenos sociales vinculados a las violencias, las injusticias, la corrupción y las prácticas de conflictos negativos que fueron históricamente reflexionados por las escuelas tradicionales/positivistas que instauraron modelos orientados a la legitimidad de los discursos lineales, de validez normativa, empíricos y técnico-científicos sobre la paz, el conflicto y la violencia, siendo funcionales a los procesos de dominación desde la estatización de la paz sobre la sociedad civil y la ciudadanía.

La descripción tradicional sobre la violencia y la paz, según Galtung ${ }^{21}$, tiene que ver con los fundamentos estructurales, culturales y normativos que constituyen la función propia de la paz positiva, aunque en el plano histórico se reconoce que:

Los estudiosos anotan que en los años 1934 y 1945 surgen en los Estados Unidos las primeras organizaciones no gubernamentales (ONG), que después se encargarían de proliferar un nuevo pensamiento, una nueva cultura de paz y una nueva forma de vivir la vida a través de cátedras, seminarios y talleres de convivencia. En los años 20, Wright y de Richardson, con sus análisis, y Pitirim Sorokim, con sus teorías, clarificaban los motivos de la guerra. Considerándose éstos como los primeros antecedentes y padres fundadores de estudios para la paz en su versión más genuina de "paz negativa". Sin embargo, es posible afirmar que los estudios para la paz no empezaron como campo académico hasta después de los años cuarenta $y$ cincuenta del siglo pasado. ${ }^{22}$

El proceso de superar la lógica positivista de los estudios de paz tiene que ver con la importancia de articular teoría y praxis desde un plano equitativo en el marco de los procesos epistémicos inter-disciplinares que tomen distancia con la lógica disciplinar o monolítica de hacer ciencia desde un paradigma dominante en las ciencias sociales; aquí la lucha por superar los proyectos de naturaleza epistémico-colonial que desconocen las luchas de los grupos populares en medio de la reexistencia por otro mundo posible y necesarios en sus espacios $\operatorname{cotidianos}^{23}$.

20 Sandoval, Educación para la paz integral, 26.

21 Johan Galtung, Tras la violencia, 3R: reconstrucción, reconciliación, resolución (Bilbao: Gernika Gogoratuz, 1998).

22 Sandoval, Educación para la paz integral, 28.

23 Álvaro B. Márquez-Fernández, “Crisis de la episteme política del Estado moderno en América Latina”. Obtenido de: IX Corredor de 
El desafío por generar grietas en el interior de los centros de poder epistémicos, los cuales son funcionales a las demandas y requerimientos de los grupos hegemónicos del Norte-Global (Estados Unidos-Europa) ${ }^{24}$, denota la necesidad de romper con las dinámicas de la academia orgánica/liberal de naturaleza procedimental que concibe la paz como una herramienta de dominación/control estatal al servicio del sistema mundo-capitalista. Parte de esta razón demuestra la fuerte tradición eurocéntrica que cargan los estudios de paz dentro de las ciencias sociales y cómo estos han logrado de forma tardía dar el salto hacia posturas de condición más críticas y descolonizadoras que sirvan como insumo para los análisis integrales en materia de los acuerdos, consensos, disensos y tratados sobre la pacificación de los gobiernos en medio, teniendo en cuenta situaciones de violencia sistémica y bélica.

Por tal motivo, la preponderancia que existe en los estudios de paz desde las tradiciones epistémicas de los centros de investigación hegemónicos devela la necesidad de forjar modelos alternos de investigar desde abajo y adentro de las comunidades y los territorios, teniendo en cuenta la crítica radical hacia los procesos políticos, sociales y culturales que son funcionales a los intereses de los actores institucionales y van en contravía de las necesidades reales de unas ciencias sociales de carácter emancipador ${ }^{25}$.

La crítica epistémica, asumida por escuelas emergentes en el Sur-Global, aparece como una oportunidad por superar los dilemas ético-políticos de aquellas disciplinas que generaron un corpus teórico-metodológico acorde con los intereses privados de los grupos hegemónicos. Al mismo tiempo, se concibe como la posibilidad de indagar corrientes críticas y subalternas que contemplen el diálogo abierto, la interacción intersubjetiva y la praxis por constituir otros escenarios de liberación desde abajo.

Por tal motivo, la finalidad del presente artículo consiste en la problematización teórico-conceptual de la perspectiva de paz descolonizadora a partir de la experiencia intercultural y de abajo del pueblo Nasa Wes'x, Tolima (Colombia) frente a actores legales e ilegales inmersos en sus territorios, como son la guerrilla, el paramilitarismo, el narcotráfico, las bandas criminales y las fuerzas militares, lo cual devela una experiencia subalterna de paces que apuesta por la autonomía, la defensa de la vida, la tierra y la unidad por el buen vivir en comunidad en medio de una sociedad sumida en múltiples violencias estatales y sistémicas afines a los intereses del Estado moderno-capitalista.

las Ideas. Enseñanzas de la independencia para posdesafíos globales de hoy. Repensando el cambio para nuestra América (Asunción, julio de 2008). http://www.corredordelasideas.org/docs/ix_encuentro/alvaro_marquez.pdf (feb., 2020).

24 Germán Valencia, Alderid Gutiérrez y Sandra Johansson, "Negociar la paz: una síntesis de los estudios sobre la resolución negociada de conflictos armados internos", Estudios Políticos, n. ${ }^{\circ} 40$ (2012).

25 Victoria Fontan, Decolonizing Peace (Lake Oswego, USA: Dignity Press, 2012). 


\section{Aproximaciones a las epistemes de paz interculturales y descolonizadoras}

El debate por romper con los esquemas tradicionales de los estudios de paz se encuentra orientado desde la posibilidad de generar vínculos epistémicos de forma horizontal con otras áreas y enfoques del conocimiento, tal como sucede con la pedagogía, la filosofía, la antropología y los estudios de género, desde una perspectiva crítica integral, los cuales sirven para promover la pluralidad de pensamientos en torno a los diferentes fenómenos que implican algún tipo de reflexión sobre las paces, las violencias y los conflictos desde la dimensión de una episteme emergente y crítica en el sur-sur ${ }^{26}$.

Dicho contexto se constituye en el panorama de largo alcance en el que coexisten los estudios para la paz en América Latina, al ser un campo teórico-conceptual encargado de reproducir narrativas positivistas de paz perfecta, imperfecta, negativa o positiva desde la interacción con los espacios académicos, gubernamentales e investigativos de las escuelas tradicionales del saber de paces en el Norte-global ${ }^{27}$. Por ende, se proclama un tipo de conocimiento, que concibe el conflicto como una condición humana, que debe ser controlado bajo las necesidades de las instituciones en contrapelo del sentipensar de los sujetos de las comunidades, pueblos y movimientos sociales en los territorios ${ }^{28}$.

La importancia de asumir la paz como la posibilidad de establecer diálogos abiertos y desde el sentir de la otredad se configura en la oportunidad por cuestionar desde abajo a la izquierda crítica y decolonial las narrativas epistémicas normativas sobre los estudios de paz, para darle sentido a la praxis ético-política de los grupos subalternos que rompen con las tradiciones epistémicas impuestas por los entes político-académicos encargados de reproducir un conocimiento de índole privado y colonialista en el ámbito de la paz.

En la apuesta por reconocer la interculturalidad como un proceso de larga duración, que tiene presente la dialogicidad como vínculo para la superación de los conflictos desde la praxis de los de abajo, toma relevancia la necesidad de establecer espacios de deliberación de lo público y construcción colectiva de las paces desde el sentido ético de lo público, y la crítica a los esquemas hegemónicos del conocimiento propio de la colonialidad del saber, siendo contrario a la noción por descolonizar la paz e interculturalizar las relaciones de poder desde abajo que están sustentadas en obedecer de forma colectiva las necesidades, demandas y luchas colectivas en la comunidad ${ }^{29}$.

La propuesta por impulsar una perspectiva descolonizadora de la paz recae en la necesidad de generar grietas en las epistemologías dominantes, aquellas que desconocen la práctica, saberes, memorias y tradiciones de los grupos subalternos: pueblos indígenas, negros, campesinos y populares, los cuales, desde su cotidianidad, ejercen en los territorios una serie de procesos de lucha desde

26 Raúl Fornet-Betancourt, Filosofía y espiritualidad en diálogo (Mainz: Verlag Mainz, 2016).

27 Beatriz Molina y Francisco Muñoz, eds., Manual de paz y conflictos (Granada: Universidad de Granada, 2004).

28 Arturo Escobar, Sentipensar con la tierra: Nuevas lecturas sobre desarrollo, territorio y diferencia. (Medellín: Ediciones Unaula, 2014).

29 Raúl Fornet-Betancourt, ed., Crítica intercultural de la filosofía latinoamericana actual (Madrid: Trotta, 2004). 
abajo, orientados a la pacificación de situaciones desde la horizontalidad de la política $^{30}$. Asimismo, en la crítica a los proyectos de inversión público-privada que imponen un tipo de paz neoliberal pensada desde la racionalidad instrumental y los intereses de los de arriba en el marco de la generación de prácticas de extractivismo epistémico, social, económico y político en los territorios ${ }^{31}$.

La iniciativa teórica de los estudios de paz desde la dimensión de la descolonización responde a los siguientes imperativos epistémicos: (1) la crítica a los procesos de colonialidad del saber que desconocen los conocimientos provenientes de los grupos oprimidos; (2) la pluralidad de saberes propios de una ecología que apuesta por el reconocimiento de otras narrativas que establecen un diálogo intersubjetivo entre la realidad y la praxis de los de abajo; (3) la democratización de los conocimientos como una práctica orientada a superar las estructuras endogámicas de los centros e instituciones educativas modernas/ coloniales; y (4) la construcción de redes de conocimientos interculturales que logren el intercambio horizontal de experiencias, narrativas y discursos, enfocado a superar la cultura cerrada y privada propia de una élite de la investigación social anquilosada en las universidades corporativizadas y neoliberalizadas en el sistema mundo-capitalista ${ }^{32}$.

Por tal razón, la iniciativa de descolonizar la paz recaer en la oportunidad de lograr un proceso instituyente de las paces desde los grupos y actores excluidos, los cuales demandan otra forma de reconocer el conflicto para así construir escenarios que contribuyan a la canalización de las violencias; aquí emerge la capacidad de superar las brechas endémicas de la desigualdad, la pobreza y la precariedad, que afectan de forma directa a las comunidades victimas del mal desarrollo moderno-capitalista ${ }^{33}$.

La lógica de articular la paz más allá del paradigma del liberalismo para así dar oportunidad a los estudios de(s)coloniales, parte de contemplar la posibilidad de romper con el velo del colonialismo interno y epistémico que históricamente ha predominado en las estructuras modernas de la ciencia ${ }^{34}$. Al mismo tiempo, consiste en una lucha subalterna contra los grupos cerrados y mafiosos que han mercantilizado y corporativizado la narrativa de las paces en el marco de los intereses sistémicos propios de las organizaciones internacionales de carácter moderno-colonial, las cuales promueven un repertorio de la neoliberalización de la paz por medio de convenios de cooperación que pasa por encima de la autonomía en los territorios y comunidades ${ }^{35}$.

La iniciativa de romper con el velo del colonialismo interno en los estudios de paz reside en lograr incorporar aquellos conocimientos desconocidos y negados

30 Boaventura de Sousa Santos, Si Dios fuese un activista de los derechos humanos (Madrid: Trotta, 2018).

31 Zulay Díaz y Raúl Fornet-Betancourt, "Interculturalidad para la emancipación en América Latina”, Opción vol. 31, n. ${ }^{\circ} 78$ (2015).

32 Eduardo A. Sandoval, Etnografía e investigación acción intercultural para los conflictos y la paz. Metodologías descolonizadoras (Venezuela: Editorial Alfonso Arena, F. P., 2018).

33 José M. Tortosa, comp., Mal desarrollo y mal vivir. Pobreza y violencia a escala mundial (Quito: Abya-Yala, 2011).

34 Márquez-Fernández, "Crisis de la episteme política".

35 Álvaro B. Márquez-Fernández, "Presentación: La alternativa de una paz democrática”, Utopía y Praxis Latinoamericana vol. 23 (2018). 
por parte de los grupos hegemónicos sean visibilizados desde su propia lucha por emerger en medio del control y la dominación que impera en los centros epistémicos y hegemónicos del poder sistémico-colonialista ${ }^{36}$. Por ello, la necesidad de difundir aquellas experiencias alternas que van en contravía de las corrientes hegemónicas de un tipo de paz neoliberal reside en la posibilidad de reconocer las luchas populares y las resistencias comunitarias como formas instituidas de repensar desde abajo una episteme intercultural crítica que consiga explorar las cosmovisiones de los pueblos indígenas y su legado milenario en materia de defensa de la vida, la tierra, la unidad y el territorio ${ }^{37}$.

En las últimas décadas del siglo XX, las luchas socioculturales de los grupos subalternos en nuestra América representan un contexto en proceso de integración y ruptura con los esquemas tradicionales de hacer ciencia desde las directrices de los actores hegemónicos, siendo una muestra por buscar fortalecer y legitimar las epistemologías del sur y la interculturalidad como iniciativas alternas que van más allá de los marcos normativos de carácter moderno-coloniales propios del eurocentrismo epistémico, teórico, conceptual, metodológico e investigativo de nuestro tiempo ${ }^{38}$.

La crisis civilizatoria de pensamiento y praxis ético-política en el campo de la paz demuestra la preponderancia que toma la violencia estatal frente a las demandas y luchas por resistir desde abajo en el marco de los procesos de movilización y el hacer política desde la subjetividad del sujeto dentro de la sociedad $^{39}$. Una muestra de la necesidad de impulsar la construcción de la paz territorial desde los procesos de liberación de las comunidades, es la propuesta de repensar las paces como el reflejo de las experiencias en reexistencia frente a las prácticas tradicionales que conllevan a una postura cerrada con respecto a un conocimiento, un método y una metodología científico-positivista, aquella que rechaza la emergencia de las experiencias de emancipación desde los sujetos en sus diversas situaciones sobre la esfera pública.

La mirada intercultural crítica de la paz radica en la necesidad de establecer procesos de diálogo abierto y horizontal que logren cimentar un ambiente de confianza e interacción societal entre los diversos escenarios que son disimiles o divergen frente alguna situación en concreto. La paz requiere de la capacidad de superar las diferencias desde el sentipensar de la otredad, logrando reconocer los problemas, dificultades y conflictos que subyacen en la raíz de los sujetos, las comunidades y los movimientos sociales en sus distintos contextos socioculturales.

La oportunidad de un diálogo intercultural simboliza la sensibilidad emocional, espiritual, material e inmaterial del sujeto en sus dimensiones cotidiana, social, económica y política. Involucra tener la oportunidad de superar

\footnotetext{
36 Sandoval, Educación para la paz integral.

37 Cruz, "Los estudios de paz latinoamericanos".

38 Cruz y Fontan, "Una mirada subalterna”.

39 Jorge Alonso y Rafael Sandoval, "Pensar crítico y ética política en tiempos de guerra capitalista”, Utopía y Praxis Latinoamericana vol. $21, n .^{\circ} 73(2016)$.
} 
las visiones restringidas propias de la sociedad disciplinar para así articular una lógica de la ecología de saberes, lo que demostraría un canal que vincula las experiencias, las narrativas, las prácticas y las luchas de los colectivos, movimientos y grupos sociales orientados a la defensa de la vida, el territorio y el buen vivir en comunidad.

La perspectiva intercultural de los procesos de luchas populares y subalternos tiene que ver con el sentido de construcción desde debajo de la paz en los distintos escenarios socioculturales, ya que consiste en la oportunidad de establecer redes y medios que superen la lógica discursiva monolítica de los discursos coloniales y poner en tela de juicio las estructuras cerradas y endogámicas del saber y el hacer política desde arriba. Igualmente, señala la convergencia de los procesos interculturales desde adentro que logran desvincularse de las formas tradicionales de hacer política y permite la interacción horizontal sobre las luchas encaminadas a superar las necesidades colectivas y públicas de las comunidades.

El proceso de la descolonización de la paz en clave intercultural crítica radica en la necesidad de articular los siguientes enunciados analíticos desde la praxis en las dinámicas sociales, comunitarias y populares:

1. La iniciativa epistemológica del sur, orientada en articular teoría y práctica desde la ética de los más necesitados debido a que ponen en jaque las formas tradicionales de hacer ciencia desde los esquemas de los grupos hegemónicos. Por el contrario, se caracteriza por la integridad de las paces desde la praxis de la liberación y la lucha subalterna de los grupos excluidos y víctimas de la modernidad-colonialidad.

2. La perspectiva descolonizadora de la paz consiste en la oportunidad de romper con los esquemas, modelos y narrativas oficiales e institucionalizadas por el poder político hegemónico, los protocolos y acuerdos pensados desde el Norte-Global; aquí las experiencias de resistencia emanadas de las luchas subalternas de los pueblos, comunidades y movimientos sociales se instituyen en una corriente contra-hegemónica que pone en jaque los lineamientos moderno-coloniales propios de la sociedad capitalista y el Estado neoliberal.

3. La mirada crítica de la paz descolonizadora articula los procesos interculturales desde una lógica emergente de las epistemes del sur en las ciencias sociales, es decir, tiene la capacidad de establecer una dinámica de reconocimiento de la otredad desde su propia condición humana y sociocultural, siendo el reflejo de aquellas iniciativas que promueven la configuración y la ecología de saberes, de luchas, resistencias y prácticas subalternas orientadas a la pacificación democrática y popular frente a las violencias sistémicas estatales ${ }^{40}$.

Parte de esta situación revela las formas en que se constituyen las narrativas de paz desde la posibilidad del reconocimiento del otro y la deliberación de los sentires y pensares del sujeto en comunidad; aquí la concepción de los espacios de carácter público/privado representa la posibilidad de re-significar concep-

40 Jorge Alonso, "El planeta tierra, los movimientos antisistémicos y la alerta roja zapatista", obtenido de Estado y sociedad (2008). https://cdigital.uv.mx/bitstream/handle/123456789/33197/29a39ph2008n4.pdf? sequence=1\&isAllowed=y (feb., 2020). 
ciones de paz, participación, construcción y democratización desde las necesidades reales de los grupos subalternos y la visión de una ciudadanía sustantiva en la sociedad civil.

Siendo de gran importancia, reconocer que

La falta de educación intercultural senti-pensante para los conflictos y la Paz en el aula, se traduce en prácticas de racismo, exclusión, intolerancia, xenofobia, misoginia, violencia física, social, cultural y simbólica. Se desestructura la convivencia escolar teniendo en cuenta que los problemas, conflictos y violencias en el aula y la escuela se entienden como una relación social basada en la confrontación de subjetividades, intereses o necesidades entre dos o más sujetos educativos, derivados de la intolerancia y el rechazo a las diversidades. ${ }^{41}$

La visión teórica de los estudios de paz asociados a una corriente alterna de la investigación social parte de un principio ético del reconocimiento a la otredad y la deliberación de las ideas con el fin de ir más allá de las corrientes tradicionales, positivistas y mecanicistas que se encuentran en medio de una discusión teórica de la década de 1980, es decir, la concepción clásica positiva/negativa de la paz. En efecto, las lógicas teóricas de dichos grupúsculos de poder y académicos asumen la investigación de paz como un campo proclive a la resolución de los conflictos desde los intereses de los lineamientos institucionales y lineales del Estado, en donde narrativas exploradas por Lederach, Galtung y Fisas, entre otros, los convierte en los fundadores de un paradigma para la investigación de un tipo de paz monolítica, moderna y colonialista.

La lógica teórico-analítica de la epistemología de paz en el plano tradicional y positivista se caracteriza por construir informes, propuestas y protocolos desde los requisitos de los centros, universidades y grupos de investigación vinculados a las estructuras moderno-coloniales propias del capitalismo cognitivo, dándole espacio a la visión del Norte-Global que establece una corriente cerrada sobre los análisis de paz, dado que encasilla las narrativas entre la visión del Estado, las instituciones y la sociedad civil que coexisten en lo público.

De esta forma, las propuestas de:

Connotados investigadores de la paz (Galtung, Vicent Martínez, Vicenç Fisas, Francisco Muñoz, y muchos otros), consideran que los estudios en este campo tienen sus orígenes formales después de la segunda guerra mundial (siglo XX), iniciando entonces una preocupación en torno a estudiar maneras distintas de generar paz desde disimiles puntos estratégicos como el social, cultural, económico, político y educativo. ${ }^{42}$

La divergencia sobre los modelos de hacer ciencia en el campo de los estudios de paz eurocéntricos se articulan con la lógica de la modernidad/colonialidad,

41 Sandoval, Etnografía e investigación, 81.

42 Sandoval, Educación para la paz integral, 27-28. 
dado que parten de adjudicarse la pacificación como política de los Estados y la oportunidad real y factible de lograr consensos desde el ámbito de la participación ciudadana. La apuesta por emprender una perspectiva crítica desde la praxis del sujeto que tenga en cuenta la transformación de los procesos políticos desde las luchas y demandas de los abajo tiene como base legitimar las propuestas que emergen desde las iniciativas de las comunidades, territorios y grupos marginados, pues se instituye en la oportunidad de impulsar repertorios orientados a la configuración de narrativas micro/macro de paces desde la intersubjetividad propia de la experiencia del sujeto en el ámbito cotidiano de la vida pública en sociedad.

Por tal razón, la emergencia de cuestionar los estudios de paz eurocéntricos dándoles sentido a las experiencias descolonizadoras reside en la necesidad de legitimar las luchas, las resistencias y prácticas propias de los sujetos en los ámbitos colectivo y popular. Asimismo, se constituye en la necesidad de ir más allá de los discursos institucionales, normativos y procedimentales, para darles relevancia a las herramientas, demandas y propuestas que se construyen desde la praxis de los grupos subalternos. Dicho escenario se articula con un conjunto de las iniciativas enfocadas en superar el velo de la colonialidad del poder para así darle preponderancia a las iniciativas populares de los de abajo ${ }^{43}$.

La interculturalidad crítica para la paz se caracteriza por romper con las corrientes sociales conductistas y positivistas sobre el conflicto y la violencia en el análisis de las sociedades modernas puesto que reconoce la importancia de otras posturas críticas desde la acción del sujeto en la comunidad al ser un escenario que toma distancia de los esquemas monolíticos típicos de la ciencia moderno/colonial. Por el contrario, la apuesta de concretar diálogos abiertos desde la otredad en el marco de la comunicación horizontal se distingue como mecanismo para la superación de las diferencias y la resolución de los conflictos internos que constituyen las sociedades modernas en nuestros tiempos.

En este sentido, los estudios interculturales e integrales para la paz, que establecen un proceso de diálogo inter-epistémico con corrientes alternas como los análisis críticos de orden descolonial, se convierten en una apuesta por pluralizar los enfoques de la investigación social y colaborativa del sujeto en la comunidad. Sin dejar a un lado el reconocimiento de experiencias, memorias y testimonios de pueblos indígenas, comunidades populares y rurales, las cuales expresan formas de construcción desde abajo en el marco del intercambio de saberes de forma equitativa y colaborativa desde la condición humana y sentipensante del sujeto $^{44}$.

La iniciativa de los estudios para la paz interculturales desde el marco epistémico de la descolonización se identifica por generar una crítica desde adentro a los centros, institutos, revistas y academias eurocentradas del conocimiento que

43 Jaime-Salas, "Descolonizar los Estudios de Paz".

44 Xochitl Leyva Solano y Shannon Speed, “Hacia la investigación descolonizada: nuestra experiencia de co-labor", en Gobernar (en) la diversidad: experiencias indígenas desde América Latina. Hacia la investigación en co-labor, coords. Xochitl. A. Leyva y Shannon Speed (México-Ecuador-Guatemala: CIESAS/FLACSO, 2008). 
responden a los lineamientos e intereses sistémicos de Norte-Global (Estados Unidos y Europa), para así darles legitimidad a los saberes, prácticas y narrativas ancestrales, populares y subalternas de los grupos marginados de la modernidad-colonialidad.

En efecto, la condición epistémica alterna de superar los dilemas eurocentrados del conocimiento radica en la posibilidad de repensar los procesos de pacificación, resolución de conflictos y construcción de paces desde el lenguaje telúrico y popular de los grupos de abajo, aquellos que ponen en jaque los modelos político-burocráticos de implementación de los acuerdos y protocolos de paz desde una dimensión vertical, en contravía de las demandas, luchas y necesidades de las comunidades en sus territorios ${ }^{45}$.

La narrativa descolonizadora de los estudios de paz se identifica por tomar distancia de los clivajes políticos, sociales y culturales estipulados por la historia oficial (vencedores), que muestra el sentido negativo de las luchas y resistencias de los grupos populares. Por el contrario, la apuesta intercultural y descolonial se caracteriza por revitalizar los saberes de aquellos grupos marginados de la modernidad-capitalista. Al mismo tiempo, reconoce los valores olvidados producto del desconocimiento y el desprecio hacia la memoria e historia oral de los actores subalternos, que enuncian sus divergencias frente al orden impuesto desde la racionalidad hegemónica de los de arriba.

En este sentido, las experiencias, situaciones y fenómenos que configuran las resistencias de los grupos subalternos develan la oportunidad de romper con el velo eurocéntrico de los estudios de paz anglosajones, dándole espacio a los proyectos de pacificación, resolución de conflictos y transformación positiva de la violencia desde la concepción de una sociedad emancipada. Las experiencias de acuerdos de paz en el sur-global involucran una integración de saberes orientados a romper con la noción de control y sumisión por parte de los grupos hegemónicos sobre los actores en resistencia. A su vez, tiene que ver con las luchas sociales y las dinámicas políticas de los movimientos de corte feminista, anti-nuclear, ambiental, estudiantil y comunal, ya que se articulan con las luchas post-coloniales y anti-colonialistas en los territorios emergentes de paces ${ }^{46}$.

La noción teórico-conceptual de articular la paz desde la dinámica de la interculturalidad crítica tiene que ver con la posibilidad de incursionar en nuevos campos analíticos de reflexión para la investigación social en temas de paz. Del mismo modo, se instituye en la oportunidad por superar el velo colonialista de los grupos hegemónicos y dar sentido a las formas de lucha sociocultural frente a la resolución de los conflictos, lo que implicaría reconocer el valor ético-político de los actores sociales en asumen voluntad por constituir otra realidad desde su praxis y sentipensar colectivo. La capacidad de pensar la paz desde la necesidad de las comunidades en medio de sus razones, sentires y motivos que promueven la superación del conflicto en el marco de los lazos interculturales

45 Eduardo Sandoval, "Educación, paz integral sustentable y duradera”, Ra Ximhai vol. 10, n. ${ }^{\circ} 2$ (2014).

46 Fontan, Decolonizing Peace. 
entre los sujetos que logran coexistir en el interior de los diversos fenómenos implícitos en la sociedad neoliberal y el Estado capitalista, al ser los reproductores de las formas de control, violencia y dominación sobre los intereses reales de los grupos subalternos en los territorios.

La concepción descolonizadora de la paz tiene que ver con la superación de escenarios en crisis en donde preexiste de forma directa la condición y dignidad humana de la ciudadanía en la esfera pública.

\section{Ruptura epistémica y paz emergente}

Los estudios de paz desde la década de 1990 han generado grietas frente al fenómeno de neoliberalización de las ciencias sociales y el fortalecimiento del post-positivismo como paradigma que concentraría las formas de investigar desde la paz. Parte de esta situación responde a la crítica radical hecha a los modelos de concebir la pacificación desde una concepción militar, intervencionista, estatista y legalista que no responde a las luchas reales desde abajo, en donde los actores subalternos rompen con dichas concepciones gubernamentales de la implementación de modelos de paz de naturaleza neoliberal.

En la actualidad aparece la corriente epistémica alternativa de los estudios de paz, que articula procesos de larga duración en materia de investigación de conflictos, violencias y problemáticas que afectan de forma directa la paz al interior de los grupos sociales. De esta forma, la lógica de reconocer la pacificación como una práctica que proviene de las necesidades reales de los grupos subalternos tiene que ver con la crítica a la visión anacrónica de control desde el Estado, para darle sentido a la interacción y dialogicidad entre los pueblos, los movimientos y los colectivos, teniendo en cuenta las narrativas y discursos populares que permiten comprender otras visiones sobre la posibilidad de construcción de paces desde el sentipensar de las comunidades en resistencia. La interculturalidad, la etnopaz y la descolonialidad para la paz son enfoques coherentes que toman distancia de la crisis epistémica sobre la investigación tradicional en la región ${ }^{47}$.

Parte de esta propuesta teórico-conceptual sobre la paz descolonizadora se articula con la lógica teórica que pone en juicio los modelos tradicionales de pacificación para así impulsar la deconstrucción de los paradigmas, las escuelas y los centros que han constituido un discurso hegemónico en el plano de la colonialidad del saber eurocéntrico; asimismo han puesto en cuestión la razón instrumental del conocimiento positivista sobre la emergencia de una ecología de saberes de concepción popular y desde abajo, que sirve como antecedente para la compresión de las luchas socioculturales de las comunidades en sus territorios.

El reconocimiento de la descolonización en los estudios de paz como un enfoque pertinente e innovador para la investigación en las ciencias sociales resulta ser una propuesta alterna, que va más allá de la visión pragmática, normativa y tradicional, propia de la colonialidad del saber, dado que impulsa

47 Sandoval, Educación para la paz integral. 
procesos emergentes resultado del diálogo intersubjetivo entre la realidad social de los pueblos, comunidades y movimientos sociales o populares que se convierten en constructores de paces a partir de su propias experiencias y luchas en los territorios.

De esta forma, la necesidad de reconocer el campo epistémico de la interculturalidad como un escenario acorde a la oportunidad de superar situaciones de violencia sistémica, demuestra la posibilidad de promover una cultura e imaginario de superación de las diferencias mediante el diálogo abierto y solidario que consiga solventar los problemas que constituyen las distintas vicisitudes entre los sujetos y los intereses que coexisten en los distintos espacios societales. La iniciativa de constituir procesos de integración desde el sentipensar del sujeto en el marco de la interacción con escenarios locales, regionales y nacionales que sirvan como muestra de alternativas de pacificación, la no-violencia y la resolución de violencias desde la praxis ético-política de las comunidades en movimiento.

Otro aspecto que denota la descolonización de la paz desde una lectura intercultural crítica radica en la ruptura con los procesos de investigación tradicionales propios de un sistema moderno-colonial, el cual desconoce las formas de lucha, resistencia y expresión socioculturales de los grupos oprimidos. Parte de esta situación permite la articulación de experiencias de investigación desde la acción, la participación y la colaboración, teniendo presentes las demandas de las comunidades.

El postulado de asumir la descolonización de los estudios de paz desde la crítica a los modelos, enfoques y postulados tradicionales de investigación en dicho campo se instituye en la oportunidad de reconocer otras metodologías desde la praxis del sujeto y la condición de transformación del espacio social. Al mismo tiempo, apuesta por superar los lineamientos históricamente reproducidos por los grupos hegemónicos y la universidad moderno-colonial, aquella que desconoce las expresiones, sentires y luchas propias de la liberación desde la capacidad de problematizar los fenómenos como una forma de hacer ciencia a partir de la narrativa intersubjetiva de los actores en el interior de sus comunidades ${ }^{48}$.

El enfoque de la descolonización de la paz se convierte en un espacio que rompe con las nociones de la investigación para las paces, tales como positiva, negativa, constructivista, hermenéutica y clásica. Asimismo, se concibe como una oportunidad epistémica que diverge de la teoría critica tradicional y las formas de interpretación ambiguas de la violencia y el conflicto desde el marxismo ortodoxo, puesto que logra interconectar miradas como la interculturalidad de los pueblos, la praxis emergente de los subalternos y la lucha por constituir otra realidad social desde la lógica de resistencia desde abajo.

La oportunidad de incursionar por rutas innovadoras de análisis en la investigación social de la paz toma relevancia con la descolonialidad como una forma

48 Jorge Alonso, "Un sujeto a la zaga de sujetos de movimientos: pistas de indagaciones para la construcción de una teoría crítica", Utopía y Praxis Latinoamericana vol. 15, n. ${ }^{\circ} 49$ (2010). 
de abordar los fenómenos de violencia, conflicto e injusticia desde las áreas de las ciencias sociales, tomando distancia de miradas eurocéntricas de análisis socio-política. Por el contrario, propone tejer saberes desde los estudios lingüísticos, el feminismo, la narrativa, la ontosemiótica, la cultura y la memoria oral y escrita de los sujetos ${ }^{49}$.

La perspectiva de superar las visiones antiguas de las ciencias sociales, dándole paso a las formas de expresiones no-legitimadas y validadas por la ciencia moderna/colonial, simboliza la distancia epistémica con los modelos de pacificación estatal promovido por los grupos hegemónicos. Sin dejar a un lado la resistencia desde abajo que se articula con la construcción de las formas de hacer la paz desde la integración y el diálogo abierto entre los actores y las comunidades en sus territorios ${ }^{50}$.

Pues se hace necesario señalar que:

Uno de los objetivos a cumplir para el logro de una convivencia capaz de neutralizar las contradicciones que suscita la conflictividad social y las diversas causas que la generan, es la supresión de la violencia como expresión y compulsión de la fuerza que en modo alguno debe convertirse en principio de control social por parte del Estado. Es obvio que el Estado posee las competencias normativas para gerenciar la fuerza directa o indirecta en el ámbito de la vida pública, pero se trata de señalar y a la vez cuestionar, que quizás no es esta efectividad de su fuerza la que puede caracterizarlo como un Estado democrático. ${ }^{51}$

La emergencia de la descolonización de la paz se encuentra vinculada a la posibilidad de establecer un escenario de interculturalidad desde la praxis, la narrativa y los discursos de los sujetos en resistencia. A su vez se configura como una oportunidad orientada a romper con los esquemas dicotómicos/lineales de pacificación estatal, para dar el salto al reconocimiento de la integración de paces desde la educación, la cultura, la identidad, la música, el folclore y la dialogicidad de los actores o movimientos populares en los territorios.

Por tal motivo, la paz se convierte en un campo de gran relevancia para el análisis de los fenómenos políticos en el marco de los procesos de investigación social. La necesidad de indagar rutas alternas que superen las formas de control, dominación y sumisión históricamente constituidas por los grupos hegemónicos, se constituyen en un escenario que apuesta por el reconocimiento de las luchas populares y subalternas, localizadas en la praxis ético-política de los actores marginados.

La narrativa crítica de la paz se identifica por:

\footnotetext{
49 Adele E. Clarke, Carrie Friese y Rachel Washburn, eds., Situational Analysis in Practice: Mapping Research with Grounded Theory (Nueva York: Routledge, 2016).

50 Márquez-Fernández, "Presentación: La alternativa”.

51 Ibíd., 8.
} 
Los severos problemas que han ocasionado los procesos excluyentes de la producción y el consumo del Estado neoliberal han acentuado sus insuficiencias y contradicciones y su incapacidad para responder a la anomia del orden social, que lo transforma cada vez más en un sistema coactivo y punitivo. Se radicaliza su función represora y se pierde el horizonte del consenso como instancia de mediación que tiene la ciudadanía para desarrollar sus prácticas deliberativas. Es casi inevitable la situación de crisis por la que atraviesa este tipo de Estado que cada vez más, coloca en riesgo de pérdida la paz cívica. Se precipitan en el espacio público fuerzas adversas que reaccionan con intolerancia a las normas y terminan muchas veces por rebasarlo a causa de su ausencia de los escenarios donde se trama la conflictividad de realidad, porque también él termina al servicio de estrategias o alianza de clases hegemónicas enquistadas en el poder. ${ }^{52}$

La dimensión intercultural y descolonizadora de los estudios de paz se encuentra en un proceso de fortalecimiento y discusión en el marco de articular teorías, enfoques, paradigmas, métodos y metodologías desde las experiencias, casos, iniciativas y propuestas que proceden de la dinámica sociocultural y política de los movimientos, actores, comunidades y grupos subalternos que apuestan por reconfigurar las demandas, necesidades y propuestas en la esfera pública y la democratización de los poderes públicos propios de la paz y los procesos anti-hegemónicos frente al sistema mundo- capitalista y la sociedad neoliberalizada.

\section{La experiencia intercultural de paz del pueblo Nasa Wes'x, Tolima ${ }^{53}$}

La historia de la violencia sistémica en Colombia ha sido un tema de gran interés para el campo de las ciencias sociales. La necesidad de analizar las dinámicas que confluyen en la reproducción de las oleadas de pobreza, miseria y despojo en los territorios asociados a escenarios del conflicto armado entre los actores armados, tanto institucional como al margen de la ley, representa parte de la complejidad de situaciones que configura la época del conflicto bélico de larga duración en el país en el orden geopolítico de la región.

El conflicto armado, promovido por los intereses privados de grupos tradicionales y hegemónicos de la política moderna-colonial, representa un escenario que revela las construcciones de las élites de izquierda y de derecha orientadas a la obtención del poder y el control de las instituciones público-privadas al servicio de los intereses corporativos, siendo el reflejo de las dificultades que

52 Ibíd., 9.

53 Los Nasa Wes'x son un pueblo indígena que habita en el sur del departamento del Tolima (Colombia), específicamente en el corregimiento de Gaitania, perteneciente al municipio de Planadas. Como resultado del liderazgo de Tomás Valencia los Nasa Wes’x se asentaron en este territorio a fines del siglo XIX y principios del XX (1899-1906). Se conoce que su proceso de migración responde "posiblemente a causa de huir de la guerra de los Mil Días, provenientes de Belalcázar-Cauca, se asentaron en las tierras a orillas del río Atá, actual municipio de Planadas, donde constituyeron el Cabildo de la comunidad indígena Paéz de Gaitania entre 1984 y 1987, posteriormente recibieron el título de Resguardo mediante Resolución 046 del 26 de junio de 1990 otorgado por el Instituto Colombiano de la Reforma Agraria (INCORA), por el territorio que habitan, este consta de 4900 hectáreas, 433 familias y 2125 habitantes. Sin embargo, estos no son los únicos Nasa que llegaron al Tolima, varias familias se asentaron en la vereda Barbacoas municipio de Rioblanco, desde 1925, cuando canjeaban tierras en el Valle del Cauca, por tierras en el Tolima, en el año 1982 estos se constituyeron como Cabildo, reconocido legalmente por la Dirección General de Asuntos Indígenas del Ministerio del Interior y de Justicia, en 1992". [Yeison Esquivel y Boris Salinas, Memoria sonora del resguardo indígena paéz de Gaitania, Tolima. Relatos de sus músicos (Ibagué: Alcaldía de Ibagué, 2015:15)]. 
implica la construcción de una paz desde los territorios, duradera y estable, que logre agrupar las demandas de las comunidades.

La falta de oportunidades que garanticen condiciones mínimas de desarrollo y dignidad de los grupos sociales se convirtió en uno de los elementos que más influyó en la agudización prolongada de las acciones internas/externas que configuran las olas de violencias desde la racionalidad instrumental de los grupos hegemónicos en el Estado colombiano. Así pues, la importancia de lograr dar el salto de una historia marcada por el control de las mafias y los grupos de poder tradicionales sobre las instituciones, simboliza un camino que implica el diálogo, la reconciliación y una justicia real congruente con un principio de corresponsabilidad ética, que apuesta por superar las narrativas de corrupción, clientelismo y dominación por parte del Estado moderno-colonial.

El conflicto armado en Colombia ha dejado múltiples secuelas a distintos grupos de la sociedad civil; los impactos de operaciones, acuerdos fallidos y estrategias de militarización interna y externa en los territorios demuestran la complejidad de dificultades que han enfrentado los sectores más populares y marginados de una racionalidad privada propia de un Estado-capitalista, funcional al interés de la modernidad-colonial. De modo que el impacto profundo recibido por sectores como los campesinos, los indígenas, las negritudes y artesanos, entre otros, son el reflejo de las ambigüedades y daños colaterales de las violencias sistémicas del gobierno ${ }^{54}$.

El origen de la violencia desde la década de 1940 en las regiones más profundas y marginadas de la política centralista/nacional se convirtió en un factor que presionó el surgimiento de emociones, sentires y pensamientos orientados a la emergencia de procesos de rebelión, inconformidad y la aparición de grupos guerrilleros con una incipiente formación socio-política. A su vez, los problemas de ingobernabilidad y falta de instituciones fuertes que fueran coherentes con la distribución de los poderes públicos y los recursos/bienes públicos para los sectores más desfavorecidos sería parte de los elementos que impulsarían un conflicto de intereses en los territorios.

De esta forma, regiones ubicadas en el centro del país y particularmente en ciertas zonas del departamento del Tolima se instituyeron en cuna de conflictos, discusiones e interés sobre la necesidad de establecer el control de las tierras entre los sectores tradicionales: gamonales, mafias y caciques frente a los campesinos, indígenas, negritudes y grupos obreros, entre otros; dicha rivalidad sobre la redistribución de los territorios desde las necesidades reales de las comunidades, develó uno de los factores estructurales que impulsaron la violencia armada y sistémica entre los distintos grupos sociales frente a las formas de gobernar desde arriba, contrarias a las exigencias de la democratización de los poderes desde abajo.

54 Cynthia J. Arnson, et al., Los procesos de paz en Colombia: Múltiples negociaciones, múltiples actores, (Washington: Woodrow Wilson Center, Latin American Program Special Report, 2007), https://www.academia.edu/6374851/L_A_T_I_N_A_Los_procesos_de_ paz_en_Colombia_M\%C3\%BAltiples_negociaciones_m\%C3\%BAltiples_actores. 
El territorio del pueblo indígena Nasa Wes'x, ubicado en el corregimiento de Gaitania, fue escenario del choque de los intereses privados y públicos de los grupos guerrilleros, las fuerzas militares y otros actores armados criminales, que promovieron la activación de una autodefensa indígena por cuenta de proporcionar todas la herramientas materiales e inmateriales para armar a la población de los cabildos y el resguardo. En efecto, el plan proveniente del ejército resultó positivo y conllevó a una confrontación política, ideológica y armada entre los indígenas y frente a los demás actores armados, en particular con la guerrilla de las Farc-EP.

Dichos acontecimientos, que permitieron la consolidación de un entorno de violencia sistémica, tomaría fuerza con el paso del tiempo y dejaría familias resquebrajadas por el dolor de sus seres queridos caídos. Al mismo tiempo, el ambiente de división y pérdida del tejido social y comunitario sería otro factor que motivaría al pueblo indígena Nasa Wes'x en su tarea de promover los diálogos de paz frente a la guerrilla de las Farc, para así buscar un pacto de pacificación, no-militarización y superación de las experiencias negativas del conflicto armado entre ellos, teniendo en cuenta que fue promovido por el ejército nacional y las fuerzas oscuras del Estado colombiano en dicho territorio.

Por tal motivo, la experiencia de paz del pueblo Nasa Wes'x se articula con la perspectiva descolonizadora e intercultural de la paz, dado que pone en tela de juicio los esquemas tradicionales de pacificación promovidos desde los intereses y dinámicas del Estado hegemónico; por el contrario, apela a la autonomía y liberación de la madre tierra, siendo el reflejo del sentipensar desde los territorios en el marco de la construcción de paces como la motivación de sus propias luchas por otra realidad posible en el ámbito comunitario.

La lógica intercultural de vincular a otros actores no-institucionales pero que coexistieran en la región, como la Iglesia católica, la Defensoría del Pueblo y la Cruz Roja Internacional, así como algunos voceros y líderes comunales que vieron de forma positiva dicha iniciativa orientada a la construcción de un acuerdo de paz local/territorial que permitiera la pacificación de la región y la superación de las secuelas de un conflicto armado muy ajeno a los intereses del pueblo indígena pero cerca a los que mantenían los grupos hegemónicos incrustados en el poder político-colonial y mafioso del gobierno nacional.

La dimensión del acuerdo de paz de carácter subalterno promovido por la comunidad Nasa Wes' $x$ se instituye en una experiencia que demarca una ruptura epistémico-política con respecto a la concepción de pacificación y normalización del conflicto armado por parte de la institucionalidad y los grupos hegemónicos. Así pues, convergen dos planos distintos sobre la apropiación y reconocimiento de la paz desde la cosmovisión de los pueblos indígenas frente a la racionalidad instrumental de institucionalización del conflicto por parte de las estructuras estatales.

La fuerte experiencia de resistencia desde abajo, basada en matices interculturales del pueblo indígena Nasa Wes' $x$, representa un campo emergente de reflexión que rompe con los cánones de la paz moderno/liberal para darle 
sentido a la construcción de tejidos socioculturales de pacificación desde el sentipensar de las comunidades y la praxis ético-política de los grupos subalternos. Por ende, analizar de forma crítica los discursos de cada una de las fases, rutas y esquemas de negociación rompe con la dimensión vertical de imponer una racionalidad en función del capital para optar por la necesidad de superación del conflicto armado mediante el buen vivir comunitario y la pedagogía de paces en el territorio.

De esta forma, el pacto firmado el 6 de julio de 1996 simbolizaba un ejercicio de diálogo abierto en materia del reconocimiento intercultural de los actores involucrados en dicha problemática aguda de la violencia armada, lo cual reflejaba una iniciativa por darle la vuelta a la página de la "guerra ajena" para así impulsar procesos de integración en el marco del fortalecimiento de los tejidos socioculturales de las familias indígenas en su territorio.

A pesar de la inviabilidad e ilegalidad decretadas por el Estado colombiano frente a la apuesta de lograr un acuerdo local y territorial de paz por parte del pueblo Nasa Wes'x, este siguió adelante gracias a la motivación de recuperar la paz y la iniciativa de una cultura de paz que hiciera contrapeso a los sentimientos negativos encontrados por parte de los distintos actores armados en el territorios. El resultado sería una experiencia descolonizadora de paz desde abajo, que haría peso a la lógica de pacificación y reconciliación institucional promovida por los organismo internacionales, el Estado capitalista y la sociedad civil neoliberal en nuestros tiempos.

Así se evidencia en el apoyo que recibió la iniciativa de paz por parte de las mujeres Nasa:

Otra preocupación de las mujeres, era tener que ver a sus hijos repitiendo la historia de sus padres, muriendo en una guerra en la que eran utilizados como carne de cañón: "Ellas decían: gobernador yo quiero que dialoguen con la guerrilla, la guerrilla mató a mi marido, y yo luché por mis hijos y nadie me dio, aunque sea una libra de sal para mis hijos. Pero ahora mis hijos crecieron y quieren seguir lo mismo, y yo no quiero eso. Entonces gobernador dialogue con la guerrilla para que no nos mate más". (José Paya, entrevista, 23-02-2017). ${ }^{55}$

Otros aspectos positivos, posteriores a la firma del acuerdo, fueron: (1) la voluntad comunal de dar el salto de la guerra a una cultura de la paz desde abajo, que sirviera como insumo para la reconstrucción de un diálogo abierto y deliberativo desde el sentipensar de los lideres/as en su territorio. (2) La capacidad de interactuar con la alteridad de los grupos armados, en particular con la guerrilla de las Farc, al lograr cimentar una base del perdón desde el presente haciendo memoria viva de la necesidad de paz en el interior de sus familias. (3) La muestra de superar los impedimentos político-burocráticos característicos del Estado capitalista, que desconoce las iniciativas populares desde abajo, las

55 Nohora I. Barros y Santiago A. Padilla, "Sentido y memoria del acuerdo de paz Nasa Wes’x: la autonomía como posibilidad” (tesis de pregrado en Ciencia Política, Universidad de Ibagué, 2017), 75. 
cuales ponen a contrapelo las estructuras moderno-coloniales propias de la sociedad neoliberal.

La iniciativa intercultural de la comunidad indígena en medio de diálogos y reflexiones con líderes, coordinadores de proyectos, presidentes de juntas, miembros de la Iglesia católica, comerciantes y empresarios locales del municipio, emprendieron una labor de gran escala que consistió en lograr un ambiente de integración y deliberación comunitaria, orientado a buscar el camino, el desarrollo y las condiciones para la pacificación del resguardo Nasa Wes'x en el sur del Tolima.

Parte del acuerdo para avanzar en la firma y la voluntad de pacificación con la guerrilla de las Farc- EP, en donde fueron coparticipes y garantes algunos funcionarios y representantes de instituciones, entre ellos, el personero municipal, un delegado de la Cruz Roja y monseñor Luis Serna, obispo del Líbano, por parte del clero católico, fueron:

\section{Presentación:}

Según la legislación indígena, los terrenos pertenecientes al resguardo son gobernados y están gobernados solamente por los directivos del cabildo y miembros de la comunidad indígena, según la Ley 59 de 1980 y los artículos 246, 247, 329, 330 y 357. La nueva Constitución de Colombia indica que los cabildos son autónomos y podrán aplicar su propia justicia, según usos y costumbres; también velar por la paz dentro y alrededor de la comunidad y proponer soluciones de negociación para garantizar la supervivencia de sus comuneros.

Propuestas:

Artículo Primero: Quedan rotundamente prohibidas las amenazas entre campesinos e indigenas y viceversa.

Artículo Segundo: El porte de armas queda prohibido para la comunidad indígena y campesina en general, dentro del resguardo y territorio indígena; toda arma que quede decomisada dentro del resguardo y territorio indígena será destruida ante testigos del cabildo sin derecho a apelación a la decisión tomada.

Artículo Tercero: Todo indígena que ingrese, colabore con alzados en armas, Policía, Ejército, cooperativas de seguridad, quedará inmediatamente excluido del resguardo indígena y perderá los derechos y garantías indígenas.

Artículo Cuarto: Los delitos de hurto que sucedan en el resguardo, serán castigados y sancionados por la autoridad indígena competente, según usos y costumbres; en caso de incidencia y de mayor gravedad, serán trasladados a la justicia penal competente, para que sean castigados por la Ley.

Artículo Quinto: No se permitirá la estadía de grupos militares, cooperativas de seguridad o alzados en armas dentro del resguardo en territorio indígena.

Artículo Sexto: Cualquier problema que sea denunciado por un miembro indígena ante los jefes alzados en armas, será transferido por el grupo a la autoridad indígena competente.

Artículo Séptimo: Todo miembro de la comunidad no pagará cualquier clase de impuesto a los alzados en armas o cooperativa de seguridad.

Artículo Octavo: Los puntos anteriormente tratados y convenios, serán comunicados a todos los frentes de las Farc EP que operan en este sector, inclusive al secretariado general de las Farc. 
Artículo Noveno: El anterior convenio será fiscalizado y velado para su fiel cumplimiento por las entidades oficiales como las asesorías municipales, autoridades eclesiásticas, delegados de derechos humanos, Cruz Roja y asuntos indígenas.

Artículo Décimo: Léase y cúmplase.

Firmado el 26 de julio de 1996

"Jerónimo Galeano" (Por las Farc).

Virgilio López (Representación cabildo)

Testigos, Cruz Roja Internacional; por parte el clero, monseñor Luis Serna de Líbano. ${ }^{56}$

En efecto, el acuerdo de paz emprendido por la comunidad Nasa Wes'x representa un caso excepcional en medio de un escenario de violencia armada sistémica y profunda que coexiste en la realidad política colombiana. La capacidad de establecer puntos en común en medio de las dificultades, sentimientos y emociones encontradas en diversos actores, implicó la capacidad de lograr una interlocución con la otredad desde su propia condición humana, resultó ser una iniciativa que superó las visiones monolíticas propias de los modelos de paz desde arriba, para darle vitalidad a las experiencias descolonizadoras de paces desde abajo y en los territorios.

\section{CONCLUSIÓN}

La experiencia de paz intercultural y de abajo esbozada en la presente reflexión refleja la capacidad de articular narrativas descolonizadoras desde el sentipensar de las comunidades. La tarea de romper con los paradigmas tradicionales y funcionales al poder hegemónico de los grupos tradicionales sumidos en formas de control, manipulación y sometimiento, vulnerando las luchas, demandas y necesidades de los actores subalternos, se constituye en un horizonte encaminado a promover análisis en esta dimensión de los estudios de paz en el sur-sur.

En efecto, la descolonización de la paz en la región atravesó por diferentes momentos, circunstancias y razones que rompieron con la dimensión lineal/ liberal de la pacificación desde las instituciones modernas-coloniales, las cuales responden a un patrón de dominación funcional a las dinámicas de la sociedad neoliberal y el Estado-capitalista en nuestros tiempos. El proceso de acuerdos desde abajo y diálogo abierto entre diferentes partes demuestra ir más allá de los discursos impuestos desde las élites para darle sentido a la praxis ético-política de los actores subalternos que apuestan por escenarios de paz desde la liberación de sus territorios.

Las epistemes interculturales de paz en Latinoamérica simbolizan un camino de larga duración articulado con la lógica de la descolonización del saber y la crítica a los procesos de orden moderno-coloniales propios de un tipo de ciencia

56 Ibíd., 84-85. 
monolítica, positivista y privada, la cual se encuentra a contravía de las luchas y sentipensares de las comunidades que ven más allá de la dimensión institucionalizada del poder político hegemónico.

El sentipensar emprendido por las comunidades Nasa Wes'x en su ardua tarea de superar la dimensión de la paz desde la legalidad del Estado, logra demostrar la complejidad que implica la temática de los proyectos autonómicos, de resistencia y liberación emprendido por los pueblos indígenas en sus territorios. Asimismo, la posibilidad de constituir acuerdos y puntos en común que superen la narrativa de la violencia, el odio y el resentimiento sobre la otredad, refleja la posibilidad de construcción de paces desde el sentir colectivo y público que impera más allá de los valores privados, mercantiles y cerrados de la paz neoliberal.

En últimas, la paz en Colombia no consiste propiamente en un acuerdo firmando y refrendado por las élites a través de las instituciones público-privadas, sino la posibilidad de sumar voluntades que superen la racionalidad privada e instrumental propia de la sociedad neoliberal y el Estado-capitalista. Posiblemente, la apuesta radica en aprender desde la experiencia de otras epistemes que muestran la capacidad de los procesos interculturales críticos que logren un diálogo abierto y deliberativo desde el sentir, las necesidades y las demandas desde los grupos subalternos, teniendo como base las condiciones materiales, inmateriales y espirituales que residen en sus territorios.

\section{REFERENCIAS}

Alonso, Jorge. "El planeta tierra, los movimientos antisistémicos y la alerta roja zapatista". Obtenido de Estado y sociedad (2008): https://cdigital.uv.mx/bitstream/handle/123456789/33197/2 9a39ph2008n4.pdf?sequence=1\&isAllowed=y (feb., 2020).

Alonso, Jorge. "Un sujeto a la zaga de sujetos de movimientos: pistas de indagaciones para la construcción de una teoría crítica". Utopía y Praxis Latinoamericana 15, n. ${ }^{\circ} 9$ (2010): 35-52.

Alonso, Jorge y Rafael Sandoval. "Pensar crítico y ética política en tiempos de guerra capitalista". Utopía y Praxis Latinoamericana 21, n. ${ }^{\circ} 73$ (2016): 11-13.

Alvear, Julio César. "La paz neoliberal: el postulado de la razón instrumental sobre la razón dialógica". Criterio Jurídico 8, n. ${ }^{\circ} 2$ (2008): 147-169.

Arnson, Cynthia, Jaime Bermúdez, Darío Echeverri, David E. Henifin, Alfredo Rangel y León Valencia.. Los procesos de paz en Colombia: Múltiples negociaciones, múltiples actores. (Washington D.C.: Woodrow Wilson Center, Latin American Program Special Report, 2007), https://www.academia.edu/6374851/L_A_T_I_N_A_Los_procesos_de_paz_en_Colombia_M\%C3\%BAltiples_negociaciones_m\%C3\%BAltiples_actores.

Barros, Nohora I. y Santiago A. Padilla. "Sentido y memoria del acuerdo de paz Nasa Wes'x: la autonomía como posibilidad". Tesis de pregrado en Ciencia Política, Universidad de Ibagué, 2017, 75.

Clarke, Adele E., Carrie Friese y Rachel Washburn,. Situational Analysis in Practice: Mapping Research with Grounded Ttheory. Nueva York: Routledge, 2016.

Cruz, Juan. “Reseña del libro Descolonización de la paz de Victoria Fontan. Ra Ximhai 10, n. 2 (2014): 265-269.

Cruz, Juan. "Los estudios de paz latinoamericanos en la encrucijada. Producir o reproducir, una mirada desde las epistemologías del Sur". Revista CoPaLa 3, n. 5 (2018): 9-21.

Cruz, Juan y Victoria Fontan. "Una mirada subalterna y desde abajo de la cultura de paz". $R a$ 
Ximhai 10, n. ${ }^{\circ} 4$ (2014): 135-152.

De Sousa Santos, Boaventura.. "Colombia entre la paz neoliberal y la paz democrática" (2017). Obtenido de Kavilando: https://kavilando.org/index.php/2013-10-13-19-52-10/confllicto-social-y-paz/5223-colombia-entre-la-paz-neoliberal-y-la-paz-democratica-1 (feb., 2020).

De Sousa Santos, Boaventura. Si Dios fuese un activista de los derechos humanos. Madrid: Trotta, 2018.

Díaz, Zulay. "Pensar del sujeto interdiscursivo en el diálogo intercultural". Utopía y Praxis Latinoamericana 18, n. 60 (2013): 69-79.

Díaz, Zulay y Raúl Fornet-Betancourt. “Interculturalidad para la emancipación en América Latina”. Opción 31, n. ${ }^{\circ} 78$ (2015):145-156.

Escobar, Arturo. Sentipensar con la tierra: Nuevas lecturas sobre desarrollo, territorio y diferencia. Medellín: Ediciones Unaula, 2014.

Esquivel, Yeison y Boris Salinas. Memoria sonora del resguardo indígena Paéz de Gaitania, Tolima. Relatos de sus músicos. Ibagué: Alcaldía de Ibagué, 2015.

Fontan, Victoria. Decolonizing Peace. Lake Oswego, USA: Dignity Press, 2012.

Fornet-Betancourt, Raúl, editor. Crítica intercultural de la filosofía latinoamericana actual. Madrid: Trotta, 2004.

Fornet-Betancourt, Raúl. Filosofía y espiritualidad en diálogo. Mainz: Verlag Mainz, 2016.

Galtung, Johan. Tras la violencia, 3R: reconstrucción, reconciliación, resolución. Bilbao: Gernika Gogoratuz, 1998.

Harto de Vera, Fernando. "La construcción del concepto de paz: paz negativa, paz positiva y paz imperfecta". Cuadernos de estrategia, n. 183 (2016): 119-146.

Jaime-Salas, Julio. “Descolonizar los Estudios de Paz, un desafío vigente en las Ciencias Sociales en el marco de la neoliberalización epistémica contemporánea". Revista de Paz y Conflictos 12, n. ${ }^{\circ} 1$ (2019): 133-157.

Jiménez, Francisco. "Hacia un paradigma pacífico: La paz neutra". Convergencia. Revista de Ciencias Sociales, $n .^{\circ} 1$ extraordinario (2009): 141-189.

Leyva Solano, Xochitl y Shannon Speed. “Hacia la investigación descolonizada: nuestra experiencia de co-labor". En Gobernar (en) la diversidad: experiencias indígenas desde América Latina, coordinado por Xochitl Leyva y Shannon Speed. México-Ecuador-Guatemala: CIESAS/FLACSO, 2008, 65-108.

Márquez-Fernández, Álvaro B. “Crisis de la episteme política del Estado moderno en América Latina". Obtenido de: IX Corredor de las Ideas. Enseñanzas de la independencia para posdesafíos globales de hoy. Repensando el cambio para nuestra América (Asunción, julio de 2008). http://www.corredordelasideas.org/docs/ix_encuentro/alvaro_marquez.pdf (feb., 2020).

Márquez-Fernández, Álvaro. "Presentación: La alternativa de una paz democrática". Utopía y Praxis Latinoamericana 23 (2018): 8-9.

Medina Muñoz, Ignacio, coordinador. Democracia sub-alterna y Estado Hegemónico. Crítica política desde América Latina. Diálogo abierto con Álvaro B. Márquez-Fernández. Buenos Aires: El Pregonero-Elaleph.com S.R.L., 2018.

Molina, Beatriz y Francisco Muñoz, editores. Manual de paz y conflictos. Granada: Universidad de Granada, 2004.

Sandoval, Eduardo. "Educación, paz integral sustentable y duradera". Ra Ximhai10, n. 2 (2014): 115-133.

Sandoval, Eduardo. "Educación indígena zapatista para la paz y la no-violencia". Espacio Abierto 25, n. ${ }^{\circ}$ 1) (2016): 23-36.

Sandoval, Eduardo. Educación para la paz integral - Memoria, interculturalidad y decolonialidad. Bogotá: ARFO, 2016.

Sandoval, Eduardo. Etnografía e investigación acción intercultural para los conflictos y la paz. Metodologías descolonizadoras. Venezuela: Editorial Alfonso Arena, F. P., 2018.

Tortosa, José M., compilador. Mal desarrollo y mal vivir. Pobreza y violencia a escala mundial. Quito: Abya- Yala, 2011.

Valencia A., Germán, Alderid Gutiérrez L., y Sandra Johansson. “Negociar la paz: una síntesis de los estudios sobre la resolución negociada de conflictos armados internos". Estudios Polí- 
ticos, n. ${ }^{\circ} 40$ (2012): 49-174.

Wallerstein, Immanuel, coordinador. Abrir las ciencias sociales: Informe de la Comisión Gulbenkian para la reestructuración de las ciencias sociales. México: UNAM / Siglo XXI, 1996.

Wallerstein, Immanuel. Análisis de sistemas-mundo. Una introducción. México: Siglo XXI editores, 2005.

Wallerstein, Immanuel. Historia y dilemas de los movimientos antisistémicos. Bogotá: Ediciones desde abajo, 2008.

\section{Cómo citar:}

Sandoval-Forero, Eduardo Andrés; Capera Figueroa, José Javier. "Una aproximación a la descolonización de los estudios de paz: la experiencia intercultural y de abajo del pueblo Nasa Wes'x Tolima, Colombia". Revista Historia de la Educación Latinoamericana. 22 No. 35 (2020): 181-207 https://doi.org/10.19053/01227238.11939

(c) (1) @) Esta obra está bajo una licencia Creative Commons. Reconocimiento-No Comercial-Sin Obra Derivada 2.5 Colombia. 
